\title{
A review of computer-aided design of paints and coatings
}

Jhamb, Spardha; Enekvist, Markus; Liang, Xiaodong; Zhang, Xiangping; Dam-Johansen, Kim; Kontogeorgis, Georgios M

\section{Published in:}

Current Opinion in Chemical Engineering

Link to article, DOI:

10.1016/j.coche.2019.12.005

Publication date:

2020

Document Version

Peer reviewed version

Link back to DTU Orbit

Citation (APA):

Jhamb, S., Enekvist, M., Liang, X., Zhang, X., Dam-Johansen, K., \& Kontogeorgis, G. M. (2020). A review of computer-aided design of paints and coatings. Current Opinion in Chemical Engineering, 27, 107-120. https://doi.org/10.1016/j.coche.2019.12.005

\section{General rights}

Copyright and moral rights for the publications made accessible in the public portal are retained by the authors and/or other copyright owners and it is a condition of accessing publications that users recognise and abide by the legal requirements associated with these rights.

- Users may download and print one copy of any publication from the public portal for the purpose of private study or research.

- You may not further distribute the material or use it for any profit-making activity or commercial gain

- You may freely distribute the URL identifying the publication in the public portal 


\title{
A Review of Computer-Aided Design of Paints and Coatings
}

Spardha Jhamb ${ }^{\mathrm{a}, \mathrm{b}}$, Markus Enekvist ${ }^{\mathrm{a}, \mathrm{b}}$, Xiaodong Liang ${ }^{\mathrm{a}, \mathrm{b}}$, Xiangping Zhang ${ }^{\mathrm{c}}$ Kim Dam-Johansen $^{\mathrm{b}}$, Georgios M. Kontogeorgis ${ }^{\mathrm{a}, \mathrm{b}^{*}}$

${ }^{a}$ CERE, Department of Chemical and Biochemical Engineering, Technical University of Denmark, Building 229,

Søltofts Plads 229, DK-2800, Kgs. Lyngby, Denmark

${ }^{b}$ CoaST, Department of Chemical and Biochemical Engineering, Technical University of Denmark, Building 229,

Søltofts Plads 229, DK-2800, Kgs. Lyngby, Denmark

${ }^{c}$ Beijing Key Laboratory of Ionic Liquids Clean Process, CAS Key Laboratory of Green Process and Engineering, State Key Laboratory of Multiphase Complex Systems, Institute of Process Engineering, Chinese Academy of Sciences, Beijing 100190, China

*Corresponding author

Email address: gk@kt.dtu.dk

\begin{abstract}
There is an immense potential for the computer-aided tools in the design of paints and coatings. Significant advances have been made, involving also the use of thermodynamic and in general property models for the study and theoretical formulation of these products. Algorithms and tools based on such models enable the formulation chemist to speed up the design process, by allowing them to focus their experimental efforts on a selected number of reliable constituents for the coating formulation.

Even though model-based methods and tools can save resources and time required for the design, service life prediction and formulation of new products, the experimental validation cannot be done away with; as certain interactions in these complex systems can be accounted for only by using practical design procedures.

Machine learning algorithms can, however, be used to improve the accuracy of predictive methods, if sufficient data on observed anomalies from physicochemical based theoretical predictions, is available.
\end{abstract}

KEYWORDS: Computer-Aided Tools, Thermodynamics, Property Models, Algorithms, Coating Design

\section{Introduction}

Design of complex (formulated, multicomponent) chemical products is now considered to be a widely accepted area of teaching ${ }^{1-4}$ and research ${ }^{5}$ in chemical (and biochemical) engineering, as it has been 
previously the case for other engineering disciplines like mechanical engineering. Some researchers have claimed that this field can be a third or emerging paradigm in chemical engineering ${ }^{6-10}$, but of course in order for this to be the case it is necessary to have a systematic methodology and accompanied tools for the design of complex (bio-) chemical products. Many have worked in this area ${ }^{11-17}$. One pioneer in this field, has demonstrated how a systematic computer-aided design (CAD) methodology, supplemented by a wide range of predictive tools for estimating the necessary properties, can be used for a wide range of formulated products, also those which include polymers, surfactants, emulsifiers, solvents and other compounds ${ }^{18-20}$.

A particular case of complex formulated products, with a very long history of production and use, is the paints and coatings. Paints and coatings consist of a wide range of components (polymers, pigments, solvents, additives), as shown in Figure 1. Solvents make up sometimes over 50\% (by volume) of the paint formulation, which, after drying and curing, consist mostly of the polymer(s) and pigments.

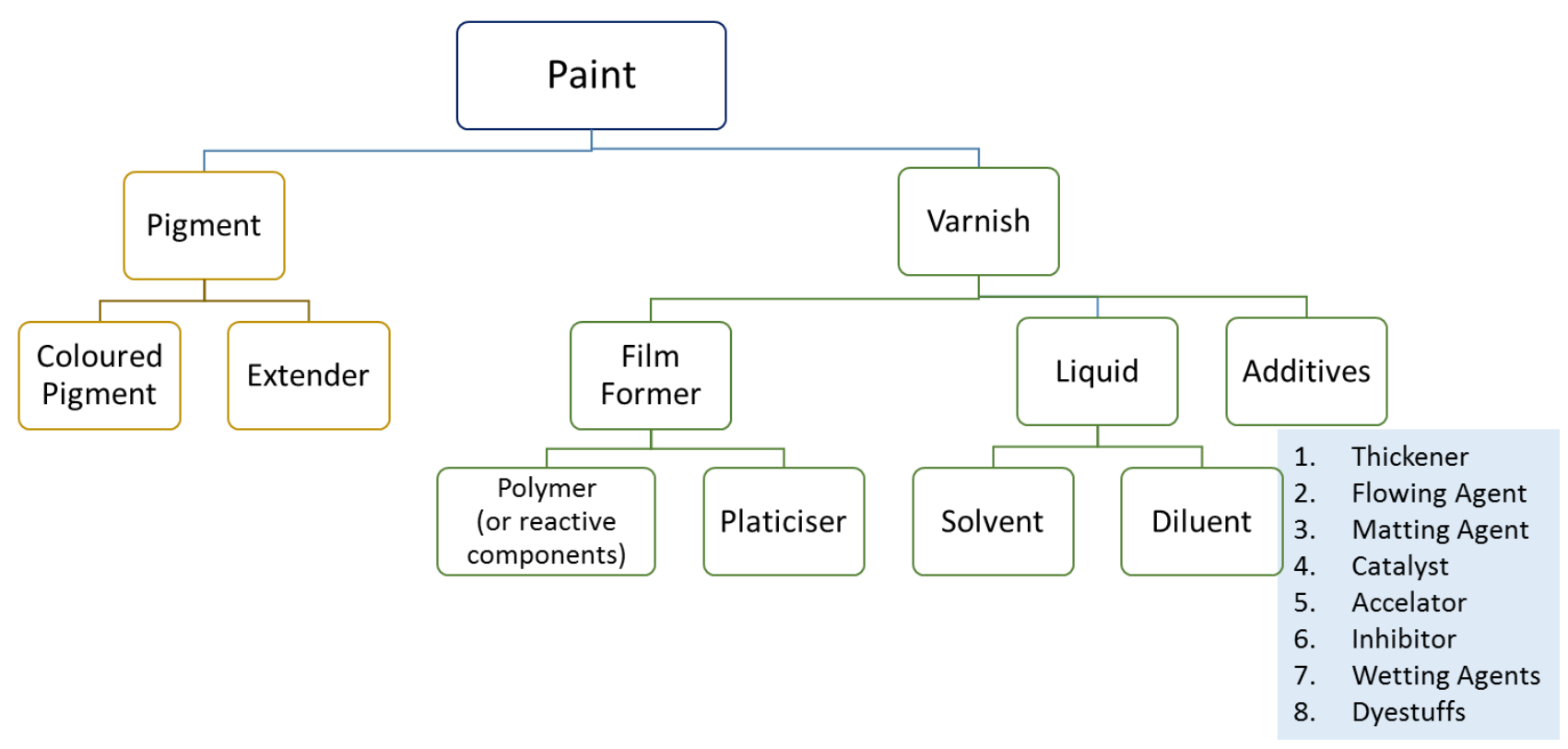

Figure 1. The main ingredients of a paint formulation (adapted from Turner, 1988) ${ }^{21}$

The properties of paints and coatings depend, often in a rather complex way, on the interactions between the different components. These properties can be categorized in more than one ways e.g. non-equilibrium or transport properties (like chemical reactivity, flow behavior - viscosity and diffusion) that are ratedependent, equilibrium or material properties (like vapor pressure, liquid-liquid phase separation, solubility, wettability and surface tension - adsorption) that are rate-independent, and combined properties like the evaporation rate or the adhesion ${ }^{22}$.

The equilibrium and non-equilibrium properties can be further classified into bulk-phase properties and surface-phase properties. The bulk-phase properties are those which are influenced only by other molecules or material within the formulation, while the surface properties are those which are influenced by the other material which forms the interface with the formulation ${ }^{23}$. Alternatively, the paint properties can be classified according to the type of the key ingredients in paint and are summarized in Figure 2. Moreover, it is important to note the distinction between the "bulk" properties of the liquid paint and the properties of the 
final dry paint. The properties of the final dry paint are also affected by different drying mechanisms and polymer selection.

An important aspect in the design of paints and coatings is to formulate products with the desired characteristics and while the experimental approach has by far dominated in the coatings industry, the collection of experimental data, the development of predictive property estimation methods and the use of computer-aided techniques can be highly useful in this context.

As mentioned, paints are complex products and the link between the bulk-phase properties and the final "dry paint" properties, is a key aspect in the aforementioned design process. However, the focus of this review is on the "bulk-phase" properties. As mentioned often in literature ${ }^{22,24,25}$, knowledge of the bulk-phase properties is often indicative of many surface phenomena and largely responsible for the final performance of the paint. The same can be said of the equilibrium and non-equilibrium properties and a clear link between them often exists. For example, the preferential adsorption of substances onto solid surfaces from a liquid solution depends to a large extent on their solution properties. Surface tension, wettability and adhesion are related. The viscosity of a polymer solution is sensitive to the quality of the solvent and the mass-transfer process in solvent evaluation and drying depends on both the vapor-liquid equilibrium (VLE) and liquidliquid equilibrium (LLE) properties.

As the well-defined bulk-phase properties (equilibrium and non-equilibrium) of polymer solutions and of the components of paints have this far-reaching significance in coatings technology, this work focuses on them and describes progress made in their understanding, prediction and use in a computer-aided framework. 


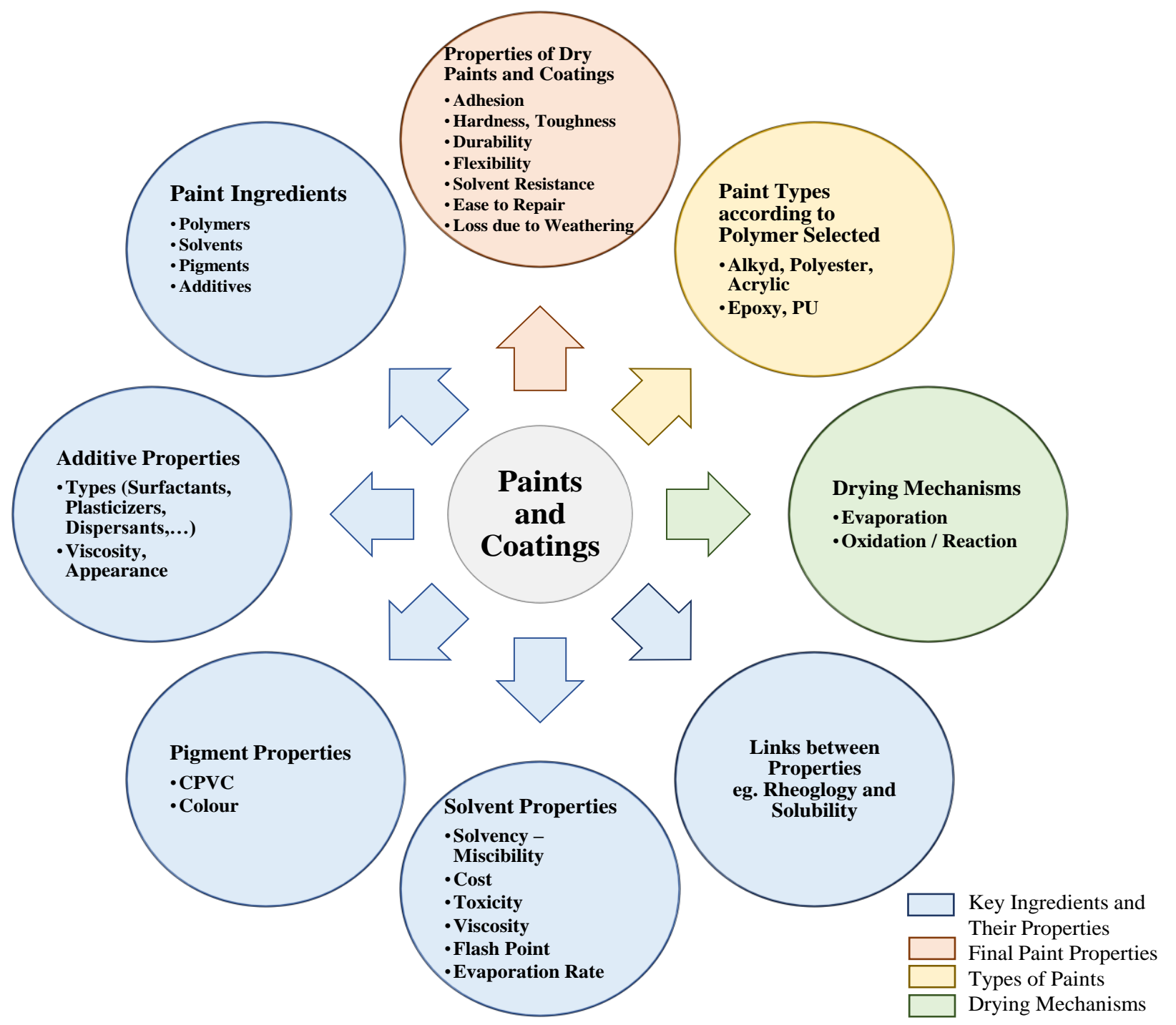

Figure 2. Key Ingredients, Their Properties, Drying Mechanisms and Types of Paints that Play an Important Role in Determining the Final Properties of Paints and Coatings

\section{Modelling and Prediction of Thermodynamic and Combined}

\section{Properties}

Thermodynamic properties are crucial in coatings technology, both in the formulation business ("the like dissolves like" rule is well-accepted) and, directly or indirectly, in a wide range of other phenomena such as stability of paint dispersions, swelling, rheology, surface adsorption and drying-evaporation. Besides formulation (finding suitable solvents for binders), the importance of phase equilibria can be felt in many coatings-related situations. For example, during solvent evaporation in the drying process the stability of the system may change, and problems sometimes reported about drying are related to the instability, which leads to the formation of two liquid phases with different overall rheology ${ }^{24}$. Another situation is when adhesion problems reported are associated with instabilities caused by the migration of non-evaporating species like plasticizers, thickeners and surfactants to the interface. Finally, in order to estimate the protective properties of different coatings, it is also important to know the interactions between cross-linked polymers and other species like additives in the coatings, external solvents and vapors. 
Considering the complexity and multicomponent nature of coating formulations, it is crucial to have relatively simple and predictive models when such properties are concerned, especially if the results are to be implemented in a CAD system. Over many years and still today, the solubility parameters especially the Hansen Solubility Parameters (HSP) have been widely used ${ }^{21,26}$. This tool is simple and can be used not only to determine the compatibility of solvents and polymers but also for solvents and pigments. Moreover, predictive group contribution (GC) methods have been developed over the years for HSP ${ }^{27}$, which greatly facilitates the use of the method in a CAD environment, as discussed later. There are no predictive methods for 'Radius of Solubility', which needs to be supplied separately. The existing methods do not perform very satisfactorily for pigments, as shown in Figure 3, which calls for the development of improved methods for HSP of pigments. In most cases, HSP are used "as it is" without temperature corrections; but they can also be incorporated in a thermodynamic model framework and the Flory-Huggins/HSP method developed by Lindvig et al. ${ }^{28}$ is one way to do it.

GC methods have been developed, not just for HSP $\left(\delta_{d}, \delta_{h}, \delta_{p}\right)$, but for numerous other properties and this has facilitated the applications of CAD enormously. A review on the topic has been recently published ${ }^{29}$.
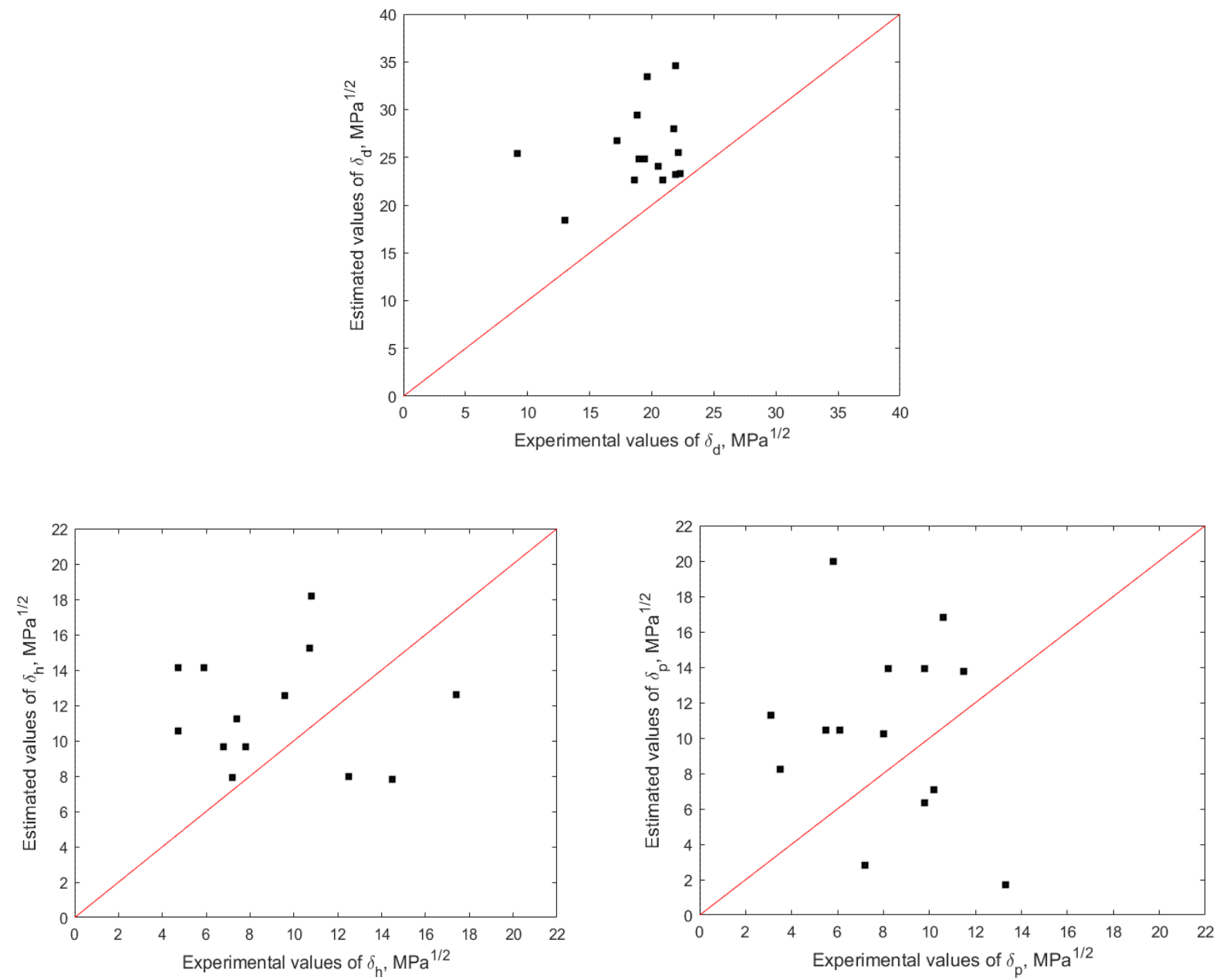

Figure 3. Prediction of Hansen Solubility Parameters (HSP) for Organic Pigments using a Second-Order Group Contribution (GC) Method ${ }^{30}$

Despite the fact that such methods based on HSP do include some approximations and assumptions in the experimental determination of the values, extrapolation to other conditions can be hazardous and GC 
methods are approximate, they are still of wide use in coatings industry, as for the very complex systems involved a compromise between simplicity and accuracy is often needed.

Holten-Andersen ${ }^{25}$ wrote more than 30 years ago "For qualitative purposes the three-dimensional solubility parameter method is excellent for evaluating the solubility of polymers in solvents. It is the belief of the author that no other present methods offer the same combination of rational foundation, simplicity and predictive power". This statement holds even today. Even though Holten-Andersen proceeds to state "for quantitative purposes, GC methods are necessary", there are many issues. For example, of crucial importance in coatings science is the prediction of LLE of systems containing multiple polymers and solvents. This is a largely unresolved problem even today. There are many thermodynamic models today for polymers (see for a review Refs. ${ }^{31-34}$ in form of GC activity coefficient models and equations of state with good or rather good performance for activity coefficients/VLE but their performance for LLE is unreliable for coatings applications. Even some of the most advanced equations of state of our times like GC versions of the SAFT theory have limited predictive applicability when it comes to multicomponent polymer-solvent LLE ${ }^{35-37}$. Thus, these models are not suitable for CAD purposes. This is not to say they are not useful; GC versions of the PC-SAFT model have been applied to LLE for a wide range of polymer-solvent systems (for a review see Refs ${ }^{34,37}$ ) and the same can be said for models like Entropic-FV ${ }^{38,39}$, a polymer extension of the wellknown UNIFAC method, but the predictive results for LLE are not consistent or reliable in all applications and much more work is needed, especially for complex polymers and solvents and for multicomponent systems, which are of importance in coating applications.

An alternative to the use of full thermodynamic models, which can be easily implemented in CAD systems, is the use of the so-called infinite dilution activity coefficients (on weight-basis) for polymer-solvent systems $\left(\Omega_{1}^{\infty}\right)$. This approach has been shown in literature ${ }^{22,24,25,28,32,33,35}$ to have a wide applicability and predictive value for fast estimation of miscibility. In these references are mentioned several simple rules of thumb e.g. $\Omega_{1}^{\infty}$ values less than 6 indicate good solubility in polymer-solvent systems (and above 8 or 10 immiscibility over the entire concentration range), while for organic solvent-water systems the limits are below 5 for miscibility and above 7 for immiscibility. These rules of thumb are derived based on the Flory-Huggins equation. Moreover, such $\Omega_{1}^{\infty}$ values can be easily calculated by predictive GC methods like UNIFAC - FV and Entropic - FV and the results of calculations for 16 systems is shown in Table 1.

The four polymers considered are Polyisobutylene (PIB), Polystyrene (PS), Polyethyl methacrylate (PEMA) and Polyvinyl acetate (PVAC). For each of the four polymers, the solvents: hexane, benzene, ethyl acetate and tetrachloromethane, are considered to estimate the $\Omega_{1}^{\infty}$ for the system. The calculations are made with the software SPECS developed at the Technical University of Denmark (CERE) ${ }^{40}$. There is a good agreement for most cases in the methods and experimental values and assessments of miscibility indicating that, both the rule of thumb and combined use with GC methods, are working well. However, in the case where the repeat unit of the polymer has a similar molecular structure to that of the solvent, the UNIFAC - FV model performs better than the Entropic - FV model. This can be seen from the predicted values of $\Omega_{1}^{\infty}$ of the systems 'polyvinyl acetate - ethyl acetate', 'polystyrene - benzene' and 'polyisobutylene - heptane'. 
Table 1. Omega $\left(\Omega_{1}^{\infty}\right)$ values (weight-based infinite dilution activity coefficients) and S/NS (solvent/non-solvent) estimations using group-contribution activity coefficient models available in the software SPECS 40

\begin{tabular}{|c|c|c|c|c|c|c|c|c|}
\hline & \multirow[b]{2}{*}{ Polymer } & \multirow[b]{2}{*}{ Solvent } & \multirow{2}{*}{$\begin{array}{c}\text { Experimental } \Omega_{1}^{\infty} \\
\text { (Holten-Andersen and } \\
\text { Eng, 1988; } \\
\text { DECHEMA 1992) }\end{array}$} & \multicolumn{4}{|c|}{$\begin{array}{c}\text { Predicted } \Omega_{1}^{\infty} \text { (with percentage deviation from } \\
\text { experimental data) }\end{array}$} & \multirow{2}{*}{ S/NS Estimation } \\
\hline & & & & \multicolumn{2}{|c|}{$\begin{array}{l}\text { UNIFAC - FV } \\
\text { (Using SPECS) }\end{array}$} & \multicolumn{2}{|c|}{$\begin{array}{l}\text { Entropic - FV } \\
\text { (Using SPECS) }\end{array}$} & \\
\hline 1 & $\begin{array}{l}\text { Polyisobutylene } \\
\text { (PIB) }\end{array}$ & $\begin{array}{l}\text { Heptane } \\
\text { Benzene } \\
\text { Ethyl acetate } \\
\text { Trichloromethane }\end{array}$ & $\begin{array}{c}6.0 \\
7.0 \\
-- \\
\left.6.0 \text { (Extrapolated }^{*}\right) \\
\end{array}$ & $\begin{array}{c}6.18 \\
7.37 \\
15.41 \\
4.43 \\
\end{array}$ & $\begin{array}{c}(3.0 \%) \\
(5.3 \%) \\
(--) \\
(26.2 \%) \\
\end{array}$ & $\begin{array}{c}5.12 \\
5.89 \\
12.33 \\
3.76 \\
\end{array}$ & $\begin{array}{c}(14.7 \%) \\
(15.9 \%) \\
(--) \\
(37.3 \%) \\
\end{array}$ & $\begin{array}{c}\mathrm{S} \\
\mathrm{S} \\
\mathrm{NS} \\
\mathrm{S} \\
\end{array}$ \\
\hline 2 & $\begin{array}{l}\text { Polystyrene } \\
\text { (PS) }\end{array}$ & $\begin{array}{l}\text { Heptane } \\
\text { Benzene } \\
\text { Ethyl acetate } \\
\text { Trichloromethane }\end{array}$ & $\begin{array}{c}-- \\
\left.4.4 \text { (Extrapolated }^{*}\right) \\
4.0 \\
-- \\
2.1 \\
\end{array}$ & $\begin{array}{l}11.55 \\
4.29 \\
5.96 \\
1.98 \\
\end{array}$ & $\begin{array}{c}(--) \\
(7.25 \%) \\
(--) \\
(5.7 \%) \\
\end{array}$ & $\begin{array}{l}7.95 \\
4.30 \\
3.92 \\
1.69 \\
\end{array}$ & $\begin{array}{c}(--) \\
(7.5 \%) \\
(--) \\
(19.5 \%)\end{array}$ & $\begin{array}{l}\mathrm{S} \\
\mathrm{S}\end{array}$ \\
\hline 3 & $\begin{array}{l}\text { Polyethyl } \\
\text { methacrylate } \\
\text { (PEMA) }\end{array}$ & $\begin{array}{l}\text { Heptane } \\
\text { Benzene } \\
\text { Ethyl acetate } \\
\text { Trichloromethane }\end{array}$ & $\begin{array}{c}\left.29.0 \text { (Extrapolated }^{*}\right) \\
\left.6.4 \text { (Extrapolated }^{*}\right) \\
\quad-- \\
\left.2.1 \text { (Extrapolated }^{*}\right)\end{array}$ & $\begin{array}{c}452.19 \\
\\
167.37 \\
180.21 \\
48.63 \\
\end{array}$ & $\begin{array}{c}(1459.3 \%) \\
\\
(2515.2 \%) \\
(--) \\
(2215.7 \%) \\
\end{array}$ & $\begin{array}{l}18.19 \\
6.49 \\
6.78 \\
2.05 \\
\end{array}$ & $\begin{array}{c}(37.3 \%) \\
(1.4 \%) \\
(--) \\
(2.4 \%)\end{array}$ & $\begin{array}{l}\mathrm{NS} \\
\mathrm{S} \\
\mathrm{S} \\
\mathrm{S}\end{array}$ \\
\hline 4 & $\begin{array}{l}\text { Polyvinyl acetate } \\
\text { (PVAC) }\end{array}$ & $\begin{array}{l}\text { Heptane } \\
\text { Benzene } \\
\text { Ethyl acetate } \\
\text { Trichloromethane }\end{array}$ & $\begin{array}{c}\left.39.0 \text { (Extrapolated }^{*}\right) \\
5.0 \\
5.3 \\
\left.1.6 \text { (Extrapolated }^{*}\right)\end{array}$ & $\begin{array}{c}50.87 \\
4.27 \\
4.71 \\
1.05 \\
\end{array}$ & $\begin{array}{l}(30.4 \%) \\
(14.6 \%) \\
(11.1 \%) \\
(34.4 \%)\end{array}$ & $\begin{array}{l}45.80 \\
4.24 \\
3.95 \\
0.98\end{array}$ & $\begin{array}{l}(17.4 \%) \\
(15.2 \%) \\
(25.5 \%) \\
(38.7 \%)\end{array}$ & $\begin{array}{l}\mathrm{NS} \\
\mathrm{S} \\
\mathrm{S} \\
\mathrm{S}\end{array}$ \\
\hline
\end{tabular}

*In this case, $\Omega_{1}^{\infty}$ is experimentally obtained at another temperature and extrapolated to $25{ }^{\circ} \mathrm{C}$ using the equation, $\Omega_{1}^{\infty}(T)=3.699\left[\frac{\Omega_{1}^{\infty}\left(T_{0}\right)}{3.669}\right]^{T_{0} / T}$ 
This tool is particularly useful in coatings applications as in many practical problems we are dealing with the dilute concentration regime e.g. during the last stages of the solvent evaporation and in water-based coatings the organic components are present in rather small concentrations.

In the aforementioned references are also provided equations for a simple dependence of $\Omega_{1}^{\infty}$ values with temperature, so that it is always used at the temperature of interest. The temperature-effect is significant and as often experimental $\Omega_{1}^{\infty}$ values are at high temperatures extrapolation methods or predictive models are needed in order to use the approach at the temperature range of interest to coatings. It is also shown that the concept is useful for the estimation of the organic solvent-distribution in two-phase systems (e.g. waterbased latex-type coatings) and thus a rather complex LLE problem is very much facilitated by the use of $\Omega_{1}^{\infty}$ concept. The $\Omega_{1}^{\infty}$ concept is also very useful in the analysis of the adsorption and solution tendencies of the A and B parts of A-B block co-copolymers often used for the steric stabilization of two-phase coating systems $^{22,24}$. Finally, an important application is in connection to the drying of coatings which may be often divided into two mechanisms; A (controlled by diffusion in the vapor phase above the liquid) and B (solvent diffusion in the polymer film). The evaporation rate under mechanism $\mathrm{A}$ depends on the solvent concentration \& vapor pressure, temperature, air velocity and non-ideality (just the solvent mixture as polymer concentration is low). As evaporation proceeds, and for polymer concentrations over $60 \%$ the solvent activities decline, the evaporation rates are reduced and at the later stages the evaporation is determined by the solvent-polymer $\Omega_{1}^{\infty}$. As this discussion indicates, this parameter is of wide applicability in coating applications and can be directly used in CAD systems. The case of the drying/evaporation rate is also of interest for another reason; it shows that in some (but not all!) cases in coatings applications, a combined or composite property can be predicted by a theory - equation which, in turns, depends on several well-defined pure compound and/or mixture properties (in this case vapor pressure and activity coefficients) which can all be estimated from predictive GC methods. Another combined property is the swelling of crosslinked polymer networks (as many polymers in coatings often are in their final state). This can be estimated by using an extension of the Flory-Huggins equation by adding a term for accounting for the elastic effects caused by the deformation during the swelling of the cross-linked polymer network ${ }^{24}$. The final equation includes parameters related to the structure of the network, which can be obtained from mechanical properties (elastic modulus) of the polymer and a thermodynamic interaction parameter, which can be estimated from $\Omega_{1}^{\infty}$ of the solvent in the uncrosslinked primary polymer molecule.

It should be emphasized that the models typically used for predicting $\Omega_{1}^{\infty}$ mentioned above e.g. Entropic-FV and UNIFAC-FV are based on well-accepted principles such as the free-volume concept important for polymer solutions combined with a local-composition model for the energetic interactions expressed in a group-contribution form so that the final model is predictive. These concepts are all useful and often highly applicable but they are not perfect. There are deviations from experimental data, even for activity coefficients, especially for systems with highly polar and/or hydrogen bonding compounds. In the latter case, the association/SAFT theories mentioned above have been developed and are useful; but even in their GC form, they lack, as previously stated, the wide applicability of activity coefficient models, at least for applications in the coatings industry. This situation may change in the future.

\section{Earlier Studies in CAD of Coatings}

In the previous section, we have identified several thermodynamic and combined properties of relevance to the design of coatings, formulation and beyond. We mentioned rules of thumb and the value of GC 
estimation methods. However, a comprehensive design with help of computers of paints and coatings requires at least three elements: i) identification of the important properties and predictive methods for their estimation, ii) a systematic methodology and iii) computational algorithms.

One of the early pioneers in the area is Dr. Dao Tsing Wu, first associated with DuPont and later as consultant and founder of DTW Associates Inc. Even though, to the best of our knowledge, these activities have not been continued, $\mathrm{Wu}$ and co-workers have made a significant contribution to the field with pioneering developments on the use of computational tools for coatings design ${ }^{41-44}$. In these publications he presents the overall methodology as well as examples from his work in DuPont where CAD has made a difference.

He recognizes that the availability of well-designed and user-oriented software is of fundamental importance for the acceptance of computer-aided methods by industry, but the lack of standardization within the coatings industry makes it difficult to develop such software. He stated this in $1987^{42}$ and in many respects it is true today 30+ years later. The interested reader can find in these publications several examples e.g. on how an acrylic polymerization model assisted in developing a procedure for the synthesis of the polymers with 5 days of computation efforts and 2-5 experimental runs, while without the use of the model a 2-3 months effort was expected. In this review, we focus only on the solvent formulation methodology. This is crucial as solvent raw material cost can be as much as one-third of the total raw material cost for coating manufacturers ${ }^{43}$ and in many coating formulations, more than $50 \%$ of the coating is made of solvents ${ }^{44}$ Moreover, solvent formulation affects many end properties like aesthetics, coverage and functional properties, often in opposing ways, which is challenging for the formulator. According to $\mathrm{Wu}$, by relating in a qualitative way the key solvent (blend) properties to end use properties and balancing the key properties can result to a computerized solvent formulation, which can be effective and efficient.

The first step of Wu's approach is to identify the key properties and develop predictive methods of models for their estimation. Due to the complexity and many components involved, only GC models are used (often UNIFAC as is or in diverse frameworks) or other simple ready-to-use approaches like HSP. The properties identified are:

- the solvent evaporation model to predict evaporation and solvent composition as function of time under specified ambient conditions (UNIFAC is used to estimate the activity coefficients needed in the model; polymer effects are neglected due to the dilute polymer concentration range)

- the polymer solubility envelope using the HSP (which also allows an approximate assessment of whether phase separation will take place or not during solvent evaporation)

- the flash point of a solvent blend estimated using the UNIFAC-based GC method (polymer and pigments- additives effect neglected)

- surface tension using a UNIFAC-based GC method (this made is rather out-of-date today)

- the solvent blend viscosity (again ignoring the polymer) using Eyring's model and a GC method based on UNIFAC for estimating the excess free energy of activation

- the boiling point of solvent mixture (also without considering polymers)

- diverse pure solvent and polymer physical properties

In the 1992 publication, Wu presented also an 8-step formulation CAD methodology which makes use of the properties and methods mentioned above. He states that an effective use of his system requires some prior 
knowledge of the desirable range of solvent blend properties and some experimentation in order to refine the formulation. The proposed methodology starts with establishing, for each polymer, the solubility parameter ranges for the solvents/solvent blends that dissolve the polymer (step 1) and then the overlap miscibility region for the multi-polymer binder (based on the mutual solubility regions of all polymers) (step 2). In step 3 , the overlap miscibility region is refined using single solvents and the film formation process of ineptest and then (step 4) the solvent evaporation rate of the blend is specified (based on previous experience or experiments). Viscosity and surface tension of blends are specified including how they will be changed during evaporation (step 5). In the crucial step 6, the CAD system is used to select solvent blends that during evaporation have solubility parameters within the overlap miscibility region (step 3) and the percentage evaporation vs. time curves march those specified in step 4. In step 7 the formulation is checked experimentally and in step 8 the constraints of steps 4 and 5 are readjusted and steps 6-8 are repeated until a satisfactory performance of the coating system is obtained.

The methodology mentioned above has been incorporated in a software tool which was marketed for a period by $\mathrm{Wu}$ and co-workers ${ }^{45}$. A short course for the use of software was also available at the time.

The advantages of the CAD approach are in solvent replacement, cost reduction and improvement of the application properties. According to $\mathrm{Wu}$, using the $\mathrm{CAD}$ system they have proposed, the formulations developed were lower in cost and a 5\% reduction in raw material could easily be realized ${ }^{43}$. In the examples showed in his publications ${ }^{42-44}$, it was possible to achieve a $30 \%$ reduction in raw material cost without affecting the application properties of the formulation. The advantages do not stop there. According to $\mathrm{Wu}^{41-}$ ${ }^{43}$, the company formulators found that the evaporation curves can be manipulated to improve different application properties like sagging, application latitude and popping. $\mathrm{Wu}^{42}$ says that correlation between model predictions and experimental observations appear to exist for most product lines.

Wu concludes from his work on a number of important advantages of the CAD approach for paints and coatings: routine application of complex theories which can be used by non-experts, gaining insights into problems difficult to assess experimentally, minimizing (but not eliminating) experimental work, examining more options and identifying optimum ones and finally having a good training and also dissemination tool for technical information. Wu also recognizes several limitations or problems such the need for multidisciplinary approach and group work in an industrial environment, time-consuming process to develop the necessary models and even lack of data and predictive methods for some of the properties and of course the approximate nature of the results. We have to say that, while much progress has been made, see also in later sections, many of these problems must still occur today as despite being 30+ years old these statements - we still see resistance in the coatings industry to adopt these methods or simply several of the problems mentioned are still actual today. This will be discussed further when we will analyze more modern approaches presented next.

Indeed, while the approach of Wu includes many of the elements of a modern CAD methodology, it involves several steps and is not entirely computerized. Moreover, the number of properties is limited. Dr. Wu together with professor Gani and co-workers have subsequently ${ }^{46,47}$ presented computer-aided mixture design methods with pre-defined property constraints using optimization algorithms and both linear and non-linear constraints for the physical properties. The newly then- developed second-order GC methods were used.

These methods, which in these publications were used for solvent design with cost as the objective function, were later extended and enhanced by Gani and co-workers for complex formulated products, as discussed in the next section. 


\section{A Modern Approach to CAD of Coating Formulations}

The systematic CAD methodology by Constantinou, Gani and coworkers ${ }^{18,46,48}$ served as a basis for the later work to extend the methodology to include more complex products, such as liquid formulations of organic coatings ${ }^{11}$. This computer-aided workflow allows for the screening of potential candidates for active ingredients, solvent selection, and additives. Later stages involve the necessary experimental verification of the chosen candidates.

The process of designing a chemical product must be based on a fundamental understanding of the relevant interactions and properties. Figure 4 Fejl! Henvisningskilde ikke fundet.illustrates the methodology developed by Conte et al. ${ }^{49}$. The first task is to define the consumer-specified needs of the product, and to translate the needs into target physicochemical properties of the raw materials. For the second task, the ingredients performing the main function, which are the pigments and polymers in a coating, are selected. The necessary properties are found either in databases or through GC models when the measured data for the property of interest is not available. The third task is to design a solvent mixture that both matches the given property constraints and is compatible with or dissolve the active ingredients. Finally, the additives are selected to correct the properties of the formulation.

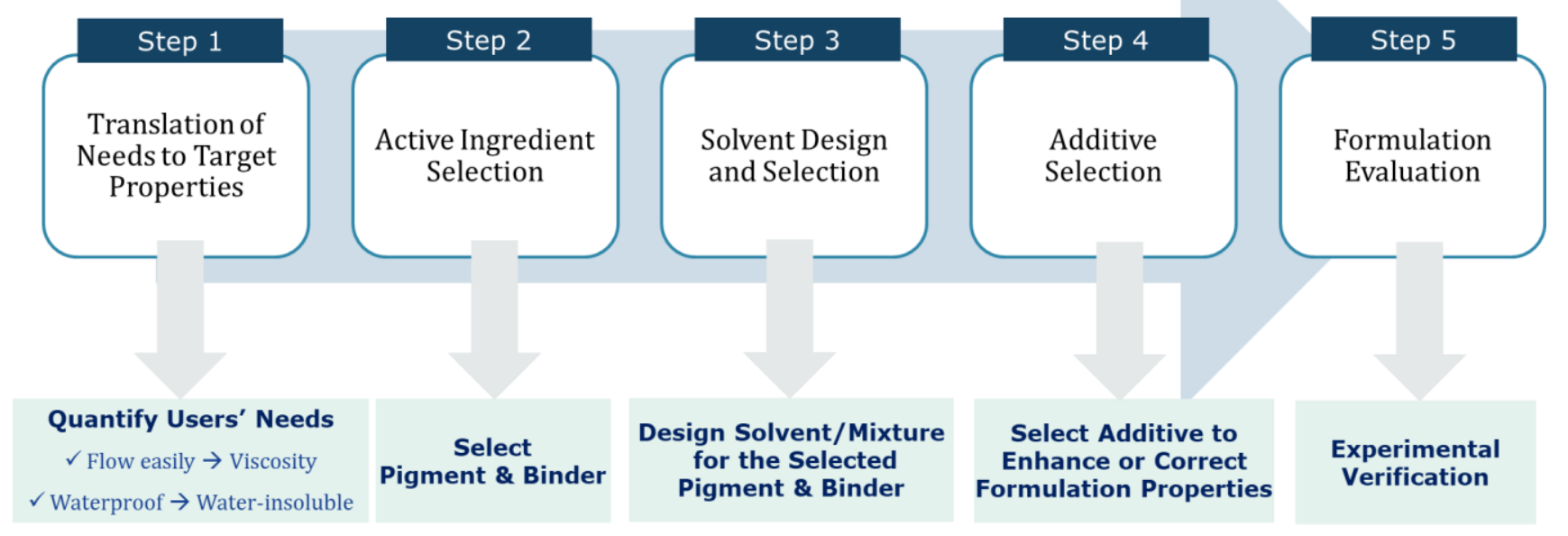

Figure 4. Framework for the CAD of coatings as implemented in vPPD-Lab

\subsection{Solvent Mixture Design for Formulation}

Solvent selection and mixture design, an essential part of CAD, has been studied extensively over the last years. Successful adaption of these methods for paints and coatings could help to significantly reduce cost and waste generation while improving the performance and reducing the environmental impact of coatings, as a significant part of a coating formulation may consist of organic solvents ${ }^{50}$.

The framework for the design of liquid based formulations developed by Conte et al. ${ }^{11}$, which is integrated in a computer-aided framework called the virtual Product Process Design Laboratory, or the vPPD-Lab ${ }^{51}$, has been successfully applied to $\mathrm{TiO}_{2}$ - based coating formulation. The computer algorithm, MIXD developed in the aforementioned work for the systematic design of thermodynamically stable binary solvent mixtures, is an efficient and reliable method. When a sensitivity analysis is performed on the constraints chosen for the design of solvent mixture, it is found that the optimum solvent is most sensitive to the constraints set on the property, evaporation time, $T_{90}$. However, other needs of an exterior coating formulation are required to be 
explored for instance, inflammability, solvency (for polymer resin) and biodegradability. Corresponding to these needs, the target properties would be flash point, HSP and biological oxidation parameter respectively. Additionally, the possibility of modelling the sensory properties like smell / odor of the solvent mixture can be useful.

Venceslau and coworkers focused on a CAD system for optimizing the cost, evaporation rate, and solubility constraints for solvents in coatings ${ }^{50}$. A case study applying the framework presents an optimal coating formulation for a given relative evaporation rate and HSP, optimized based on the cost of solvent mixture.

While solvent selection programs have been available for many years, Venceslau and coworkers ${ }^{50}$ state that trial-and-error experiments to find working solvents mixtures which fulfill target properties is still common in the industry. This implies that the software tools need to be adequately developed in order to provide a significant contribution to the coatings field.

Although Conte et al. ${ }^{11}$ developed a generic formulation methodology, it may not be comprehensive enough for the design of coating formulations. Therefore, in the work by Jhamb et al. ${ }^{52}$ an adaptation of this modelbased framework is developed wherein the third step is specifically tailored for the design of solvents for these formulations. The proposed framework takes into account the effect of properties of polymers and pigments on the choice of solvents for a specified system. Moreover, both the MIXD algorithm from the work by Conte et al. (2011) for binary solvent mixture design and the computer-aided molecular design (CAMD) algorithm developed in the work by Gani et al. ${ }^{53}$ for the design of single molecular organic solvents, are used to design solvents for a system containing acrylic polymers.

The compatibility between solvents and active ingredients is screened by solubility parameters, and either databases or pure component property prediction by GC methods is used to find the desired properties. A computer algorithm, mixture design (MIXD), then screens the candidate compounds using linear and rigorous property models. The remaining candidates can then be optimized by performance, such as a desired property or cost. An illustration of this algorithm applied to binary

solvent mixture design for a $\mathrm{TiO}_{2}$ based formulation is shown in Figure 5.Fejl! Henvisningskilde ikke fundet. A second algorithm, STABILITY, rejects any candidates that indicate a phase separation at their given compositions. The final task in

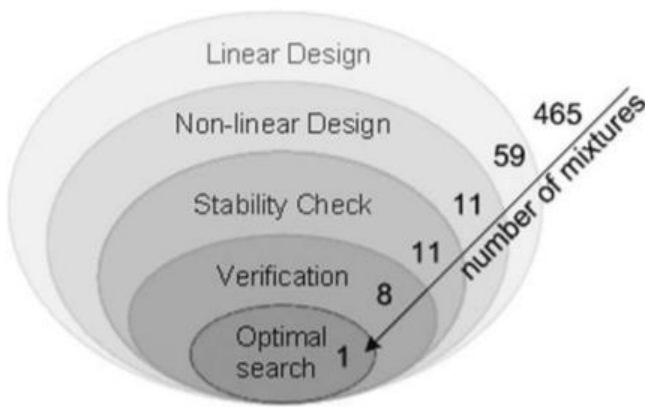

Figure 5. Illustration of the Binary Solvent Mixture Selection Framework for a $\mathrm{TiO}_{2}$ based Coating Formulation (Conte \& Gani 2011) the computer framework is to identify which qualities can be enhanced with additives, such as increased dispersion and spreadability or reduced microbial growth.

The above-mentioned approach does not only present new opportunities for design of organic coating formulations but also includes significant challenges as the complete product involves complex interactions between the different polymers, pigments, solvents, and additives. Further improvement for databases, predictive methods, and the framework can extend the usefulness of the product design system. 
Current efforts are focused on substitution of hazardous chemicals in coatings by including constraints on Environmental-, Health- and Safety- (EH\&S) related properties ${ }^{52}$ and on extending GC methods to include estimation of pure component properties for pigments. The latter is approached by inclusion of new functional groups in a multi-order GC method to better describe the molecules, as organic pigments are complex multifunctional chemicals and therefore require more structural information than current GC methods provide. High accuracy for the estimation of solubility parameters of raw materials, including pigments and polymers, is essential to correctly predict the various interactions and performance of the final product. Several theses at DTU Chemical Engineering make use of this modern CAD approach. A summary is shown in Table 2.

Table 2. PhD Theses at DTU Chemical Engineering that make use of the modern CAD Approach

\begin{tabular}{lll}
\hline Year & PhD Thesis & Products \\
\hline 2000 & Peter Harper & Mixture/Solvent design \\
\hline 2009 & Kavitha Satyanarayana & Polymer Design \\
\hline 2010 & Elisa Conte & $\begin{array}{l}\text { Solvent formulations-lotions (hairspray, insect } \\
\text { repellent, paint, sunscreen) }\end{array}$ \\
\hline 2014 & Michele Mattei & $\begin{array}{l}\text { Emulsified products } \\
\text { (hand-wash, tank-cleaning, sunscreen) }\end{array}$ \\
\hline 2014 & Nor Alafiza Yunus & Blends (gasoline, lubricants) \\
\hline 2019 & Sawitree Kalakul & $\begin{array}{l}\text { Jet-fuel blends } \\
\text { Diesel blends }\end{array}$ \\
\hline 2021 (ongoing) & Sparkus Enekvist & Chemical Substitution, Paints \\
\hline
\end{tabular}

The efforts of these researchers are not the only current attempt to use a computational approach to coating formulations. In recent years, several discussions and articles by Sander van Loon, CEO of the company Van Loon Chemical Innovations (VLCI) have been published regarding the use of HSP for paints, coatings, and ink formulations. In addition to employing the thermodynamic-based HSP for formulations and homogeneous solution design as well as Hydrophilic Lipophilic Difference - Net Average Curvature for emollient design, VLCI utilizes high-throughput experimental methods for property determination ${ }^{54}$. Information published by the company indicates advances in the methodology for raw material selection, including evidence for the selection of dispersants with overlapping solubility spheres between the pigments or fillers (Van Loon and Fricker, 2018).

\subsection{Computer-Aided Tools for Formulation Design}

Several tools based on property models and fundamentals in thermodynamics have been developed for coating formulation design. The CAMD and MIXD algorithms, mentioned in the previous section, are available via the ProCAMD tool of ICAS ${ }^{56}$ and the vPPD-Lab tool ${ }^{51}$ respectively, both developed at DTU Chemical Engineering. The generic architecture of the vPPD-Lab tool is shown in Figure 6.

HSPiP, an eBook software, contains HSP and other data on 10,000 chemicals in the current edition. Besides, the software's capability to calculate and visualize HSP in 3D, it has a solvent optimizer (up to 8 solvents, plus graphing of solvent mixture changes depending on relative evaporation rates, activity coefficients and temperature), a polymer calculator and a diffusion modeler ${ }^{57}$.

Steven Abbott's company, Steven Abbott TCNF Ltd, has developed apps based on colloid and interfacial science through the updated Kirkwood-Buff's 1950s theory and HSP technique, in order to aid practical formulators in their experimental activities ${ }^{58}$. 


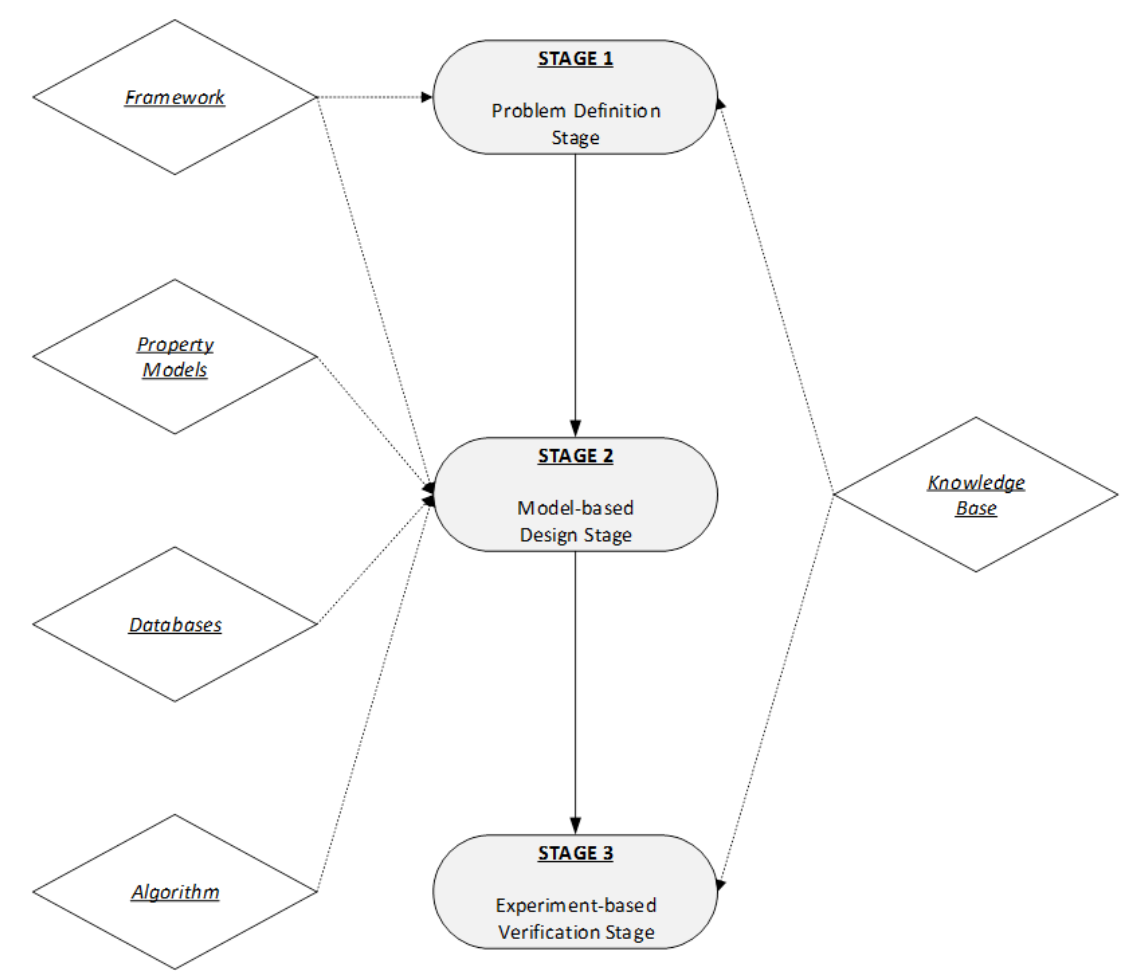

Figure 6. Generic Architecture for CAPD used in VPPD - Lab tool

\subsection{Machine Learning Algorithms for Formulation}

Another program for coating formulation, currently under development by Evonik Industries is COATINO $^{\mathrm{TM}}$, claims to be the first voice-controlled digital assistant aimed at the coatings industry ${ }^{59}$. While, as far as the authors of this article are aware, few details regarding the selection principles are available, Oliver Kröhl, who is responsible for the project, states that the program will utilize human knowledge, high throughput experimentation hardware, and software based on data and machine learning to find suitable raw materials, including additives, for the formulator ${ }^{60}$.

\section{Other Notable Applications of CAD for Coatings}

\subsection{Computer-Aided Coating Appearance Design}

Algorithms and models for color prediction have been available for many decades, as far back as 1944 (Park and Stearns, 1944). It is a field that has been approached from many sides, and for many purposes. Available color matching methods for paints and coatings often utilize spectral methods like colorimetry, standard tables like those provided by International Commission of Illumination (CIE) and statistical Artificial Intelligence methods ${ }^{62}$. Today, many different systems are available to the coating formulator for both color matching and prediction such as LargoMatch ${ }^{63}$.

Advances in computer graphics allowed for prediction of optical behavior and direct feedback to the user. For the design of automotive coatings, measurements of metallic flake finishes were used to predict hue, saturation and brightness through an interactive graphics program ${ }^{64}$. Though differences were noted for all experimental tests of the developed software, the appearance matches were determined to be adequate, and 
required no prior trial-and-error experimentation. A more recent comprehensive computer-aided appearance design system for coating formulation, based on bidirectional reflectance distribution function (BRDF) measurements, has been proposed by Kim and Lee ${ }^{65}$. BRDF defines how light is reflected at an opaque surface and is a function of illumination geometry and viewing geometry. The function takes a negative incoming light direction, and outgoing direction, both defined with respect to the surface normal, and returns the ratio of reflected radiance exiting along outgoing direction to the irradiance incident on the surface from incoming light direction. Each direction is itself parameterized by the two position coordinates, azimuth angle, zenith angle, wavelength and time; making the BRDF a twelve-dimensional function. The authors state that the appearance design of coatings is still performed by formulators based on visual inspection and experience; so, designing photorealistic predictions of coating appearance by their optical properties coupled with formulation parameters, is still a field in need of exploration. The complexity of pigmented coatings still provide significant challenges for production of coatings samples from theoretical models, but the proposed appearance design framework can provide significant value for many industrial applications.

\subsection{Prediction of Service Life}

Computational prediction of service life for coatings is a research area of high interest as experimental tests require data collection over a very long period of time and natural factors and differences in surface treatment and application lead to low reproducibility. The current method of predicting service life of industrial coatings is usually through controlled accelerated testing. The degradation of organic coatings requires an understanding of the complex relationships between exposure factors, material properties, and system performance, and can be measured by factors such as loss of functionality, adhesion, or gloss ${ }^{66}$. Several computer methods and software tools for lifetime prediction have been proposed ${ }^{67-71}$, using both statistical methods and neural networks.

\subsection{Design of Self-Stratifying Coatings}

Self-stratifying coatings is a field of coating formulation that progressed significantly during the 90's to both understand the underlying mechanism, and to create systematic computer tools to optimize the formulation. These systems provide an interesting challenge for CAD, as the multi-resinous formulation must spontaneously stratify into separate layers after application, and provide improved properties such as appearance, barriers, or adhesion. The different layers are usually separated by a gradient of the resins and can, in addition to the improved properties, provide a significant reduction in cost and time of application compared to other multi-coat systems.

An early effort to gather data on self-stratifying coatings was performed for the European Commission in 1996 to build a computer model to predict stratification by statistical analysis. The investigated properties were solubility parameters, solubility radius, surface tension and molecular weights ${ }^{72}$. Notable limitations were a lack of data for additives, pigments, and surface-treatments resulting that the study only encompassed the properties of polymers and solvents. Kinetic variables, which can prevent a thermodynamically favored self-stratification from taking place, were also omitted while building the model.

The design requirements have been discussed over the last decades, but some fundamental requirements are that of the included polymers, which must be fully compatible with the choice of solvent mixture. The compatibility has been estimated through both the HSP distance and by the overlap volume of the solubility spheres $^{73}$. Other aspects such as the evaporation rate of solvents and the surface tensions of the polymers, are also taken into account. 


\subsection{Prediction of Coating Functionality from Formulation Variables}

Various attempts have been made to predict coating functionality from formulation variables in an effort to optimize the recipe. These efforts extend over more than two decades and use polynomial models and neural networks to predict selected functional properties such as elasticity, hardness and barrier properties as a function of formulation parameters ${ }^{74}$. There are now several commercial software packages that are used to optimize the formulation of coatings ${ }^{75}$.

\section{Conclusion}

CAD is still in an early stage in the paints and coatings industrial sector and its potential is yet to be utilised to the maximum. It can prove to be extremely beneficial in terms of saving time and resources required for trial and error experimentation. Several PC-based tools and applications have been developed, which are based either on thermodynamics and physicochemical property models or on machine learning algorithms and high-throughput experimentation. However, a hybrid approach that combines the advantages of fundamentals as well as data science could potentially improve the predictability of these tools.

\section{Graphical Abstract}

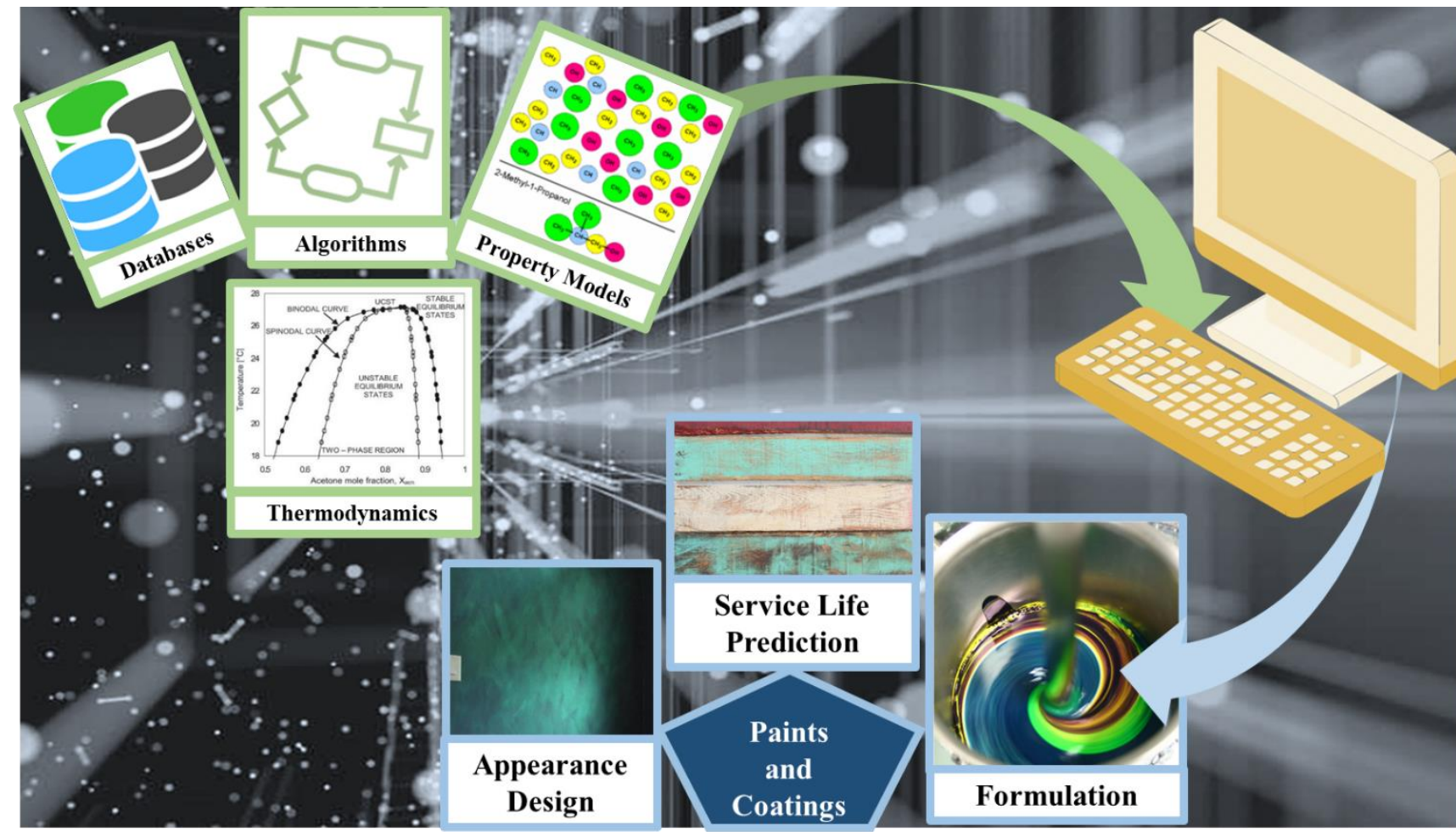

\section{References}

(1) Biegler, L. T.; Grossmann, I. E.; Westerberg, A. W. Issues and Trends in the Teaching of Process and Product Design. AIChE J. 2010, 56 (5), 1120-1125, DOI 10.1002/aic.12256.

(2) Cussler, E. L.; Moggridge, G. D. Chemical Product Design, Second Edition; 2011; Vol. 9780521168 , DOI 10.1017/CBO9781139035132.

(3) Seider, W.; Seader, J. D.; Lewin, D. Product and Process Design Principles. Synthesis, Analysis, and Evaluation; 2003; Vol. 53, DOI 10.1017/CBO9781107415324.004. 
(4) Wesselingh, J. A.; Kiil, S.; Vigild, M. E. Design and Development of Biological, Chemical, Food and Pharmaceutical Products; John Wiley and Sons Ltd, 2007.

(5) Hill, M. Product and Process Design for Structured Products. AIChE J. 2004, 50 (8), 1656-1661, DOI 10.1002/aic.10293.

(6) Costa, R.; Moggridge, G. D.; Saraiva, P. M. Chemical Product Engineering: An Emerging Paradigm within Chemical Engineering. AIChE J. 2006, 52 (6), 1976-1986, DOI 10.1002/aic.10880.

(7) Cussler, E. L.; Wei, J. Chemical Product Engineering. AIChE J. 2003, 49 (5), 1072-1075, DOI 10.1002/aic.690490502.

(8) Hill, M. Chemical Product Engineering-The Third Paradigm. Comput. Chem. Eng. 2009, 33 (5), $947-$ 953, DOI 10.1016/j.compchemeng.2008.11.013.

(9) Wei, J. A Century of Changing Paradigms. ChemTech. 1996, pp 16-18.

(10) Woinaroschy, A. A Paradigm-Based Evolution of Chemical Engineering. Chinese J. Chem. Eng. 2016, 24 (5), 553-557, DOI 10.1016/j.cjche.2016.01.019.

(11) Conte, E.; Gani, R.; Ng, K. M. Design of Formulated Products: A Systematic Methodology. AIChE J. 2011, 57 (9), 2431-2449, DOI 10.1002/aic.12458.

(12) Jhamb, S.; Liang, X.; Gani, R.; Kontogeorgis, G. M. Systematic Model-Based Methodology for Substitution of Hazardous Chemicals. ACS Sustain. Chem. Eng. 2019, 7 (8), 7652-7666, DOI 10.1021/acssuschemeng.8b06064.

(13) Kalakul, S.; Zhang, L.; Fang, Z.; Choudhury, H. A.; Intikhab, S.; Elbashir, N.; Eden, M. R.; Gani, R. Computer Aided Chemical Product Design - ProCAPD and Tailor-Made Blended Products. Comput. Chem. Eng. 2018, 116, 37-55, DOI 10.1016/j.compchemeng.2018.03.029.

(14) Karunanithi, A. T.; Achenie, L. E. K.; Gani, R. Optimal (Solvent) Mixture Design through a Decomposition Based CAMD Methodology. Comput. Aided Chem. Eng. 2004, 18, 217-222, DOI 10.1016/S1570-7946(04)80102-0.

(15) Mattei, M.; Kontogeorgis, G. M.; Gani, R. A Systematic Methodology for Design of Emulsion Based Chemical Products. Comput. Aided Chem. Eng. 2012, 31, 220-224, DOI 10.1016/B978-0-444-595072.50036-6.

(16) Ng, K. M. A Multiscale-Multifaceted Approach to Process Synthesis and Development. Comput. Aided Chem. Eng. 2001, 9, 41-54, DOI 10.1016/S1570-7946(01)80005-5.

(17) Yunus, N. A. B.; Gernaey, K. V.; Woodley, J. M.; Gani, R. A Systematic Methodology for Design of Tailor-Made Blended Products. Comput. Chem. Eng. 2014, 66, 201-213, DOI 10.1016/j.compchemeng.2013.12.011.

(18) Gani, R. Computer-Aided Methods and Tools for Chemical Product Design. Chem. Eng. Res. Des. 2004, 82 (11), 1494-1504, DOI 10.1205/cerd.82.11.1494.52032.

(19) Gani, R.; Ng, K. M. Product Design - Molecules, Devices, Functional Products, and Formulated Products. Comput. Chem. Eng. 2015, 81, 70-79, DOI 10.1016/j.compchemeng.2015.04.013.

(20) Zhang, L.; Kalakul, S.; Liu, L.; Elbashir, N. O.; Du, J.; Gani, R. A Computer-Aided Methodology for Mixture-Blend Design. Applications to Tailor-Made Design of Surrogate Fuels. Ind. Eng. Chem. Res. 2018, 57 (20), 7008-7020, DOI 10.1021/acs.iecr.8b00775. 
(21) Turner, G. P. A. and B. J. Introduction to Paint Chemistry and Principles of Paint Technology; 1988, DOI 10.1007/978-94-009-1209-0.

(22) Holten-Andersen, J., Eng, K. Activity Coefficients in Polymer Solutions. Prog. Org. Coatings 1988, 16, 77-97, DOI 10.1016/0033-0655(88)80006-2.

(23) Buckton, G. Interfacial Phenomena, Surface Tension and Liquid/Liquid Interfaces. In Interfacial Phenomena in Drug Delivery and Targeting; CRC Press, 2000; pp 1-25, DOI $10.1201 / 9781482296785$.

(24) Holten-Andersen, J., Eng, K. Solvent Activity Coefficients in Polymer Solutions. Scand. Paint Print. Ink Res. Inst. 1987, Report T2-87.

(25) Holten-Andersen, J. Physical Models and Coatings Technology. Scand. Paint Print. Ink Res. Inst. 1987, Report T12-87.

(26) Hansen, C. M. Applications - Coatings and Other Filled Polymer Systems. In Hansen solubility parameters: a user's handbook; 2007; pp 137-150, DOI 10.5860/choice.37-3905.

(27) Stefanis, E.; Constantinou, L.; Panayiotou, C. A Group-Contribution Method for Predicting Pure Component Properties of Biochemical and Safety Interest. Ind. Eng. Chem. Res. 2004, 43 (19), 62536261 .

(28) Lindvig, T.; Michelsen, M. L.; Kontogeorgis, G. M. A Flory-Huggins Model Based on the Hansen Solubility Parameters. Fluid Phase Equilib. 2002, 203 (1-2), 247-260, DOI 10.1016/S03783812(02)00184-X.

(29) Gani, R. Group Contribution-Based Property Estimation Methods: Advances and Perspectives. Current Opinion in Chemical Engineering. 2019, pp 184-196, DOI 10.1016/j.coche.2019.04.007.

(30) Stefanis, E.; Panayiotou, C. Prediction of Hansen Solubility Parameters with a New GroupContribution Method. Int. J. Thermophys. 2008, 29 (2), 568-585, DOI 10.1007/s10765-008-0415-z.

(31) Marrero, J.; Gani, R. Chapter 3: Pure Component Property Estimation: Models \& Databases. In Computer Aided Property Estimation for Process and Product Design; Kontogeorgis, G.M.; Gani, R., Ed.; 2004; pp 45-57, DOI 10.1016/S1570-7946(04)80005-1.

(32) Kontogeorgis, G.M. and von Solms, N. Thermodynamics of Polymer Solutions. In Handbook of Colloid and Surface Chemistry; Birdi, K., Ed.; CRC Press, 2014.

(33) Kontogeorgis, G. M. The Hansen Solubility Parameters (HSP) in Thermodynamic Models for Polymer Solutions. In Hansen Solubility Parameters: A Users Handbook, Second Edition; Hansen, C. M., Ed.; CRC Press, 2007, DOI 10.1201/9781420006834.

(34) Kontogeorgis, G. M.; Folas, G. K. Thermodynamic Models for Industrial Applications: From Classical and Advanced Mixing Rules to Association Theories; Wiley, 2010, DOI $10.1002 / 9780470747537$.

(35) Lindvig, T.; Michelsen, M. L.; Kontogeorgis, G. M. Liquid-Liquid Equilibria for Binary and Ternary Polymer Solutions with PC-SAFT. Ind. Eng. Chem. Res. 2004, 43 (4), 1125-1132.

(36) Tihic, A.; Kontogeorgis, G. M.; Von Solms, N.; Michelsen, M. L. A Predictive Group-Contribution Simplified PC-SAFT Equation of State: Application to Polymer Systems. Ind. Eng. Chem. Res. 2008, 47 (15), 5092-5101, DOI 10.1021/ie0710768.

(37) Tihic, A.; von Solms, N.; Michelsen, M. L.; Kontogeorgis, G. M.; Constantinou, L. Application of 
SPC-SAFT and Group Contribution SPC-SAFT to Polymer Systems-Capabilities and Limitations. Fluid Phase Equilib. 2009, 281 (1), 70-77, DOI 10.1016/j.fluid.2009.04.002.

(38) Kontogeorgis, G. M.; Saraiva, A.; Fredenslund, A.; Tassios, D. P. Prediction of Liquid-Liquid Equilibrium for Binary Polymer Solutions with Simple Activity Coefficient Models. Ind. Eng. Chem. Res. 1995, 34 (5), 1823-1834, DOI 10.1021/ie00044a033.

(39) Pappa, G. D.; Kontogeorgis, G. M.; Tassios, D. P. Prediction of Ternary Liquid-Liquid Equilibria in Polymer-Solvent-Solvent Systems. Ind. Eng. Chem. Res. 1997, 36 (12), 5461-5466, DOI 10.1021/ie970191n.

(40) DTU Chemical Engineering. SPECS - Center for Energy Resources Engineering (accessed Oct 22, 2019).

(41) Wu, D. T. Modeling and Simulation Activities in a Large Research and Development Laboratory for Coatings. ACS Symp. Ser. 1986.

(42) Wu, D. T. Modeling and Simulation in the Coatings Industry. Chemtech 1987, 17 (26).

(43) Wu, D. T. Applications of Computers in Coatings Research and Development. J. Ind. Text. 1987, 17 (1), 22-40, DOI 10.1177/152808378701700104.

(44) Wu, D. T. Computer Aided Application of Chemical Engineering Principles in the Development of Coatings. Comput. Chem. Eng. 1992, 16, S31-S42, DOI 10.1016/S0098-1354(09)80007-0.

(45) Life Science Connect. DTW Associates, Inc. (accessed Oct 21, 2019).

(46) Constantinou, L.; Bagherpour, K.; Gani, R.; Klein, J. A.; Wu, D. T. Computer Aided Product Design: Problem Formulations, Methodology and Applications. Comput. Chem. Eng. 1996, 20 (6-7), 685702.

(47) Klein, J. A.; Wu, D. T.; Gani, R. Computer Aided Mixture Design with Specified Property Constraints. Comput. Chem. Eng. 1992, 16, S229-S236, DOI 10.1016/S0098-1354(09)80027-6.

(48) Gani, R. Chemical Product Design: Challenges and Opportunities. Comput. Chem. Eng. 2004, 28 (12), 2441-2457, DOI 10.1016/j.compchemeng.2004.08.010.

(49) Conte, E. Innovation in Integrated Chemical Product- Process Design -Development through a Model- Based System Approach, PhD Thesis, Technical University of Denmark, 2010.

(50) Venceslau, E. B.; Pessoa Filho, P. A.; Le Roux, G. A. C. Application of Computer Aided Mixture Design in Paints and Coatings. In Computer Aided Chemical Engineering; 2012; Vol. 30, pp 587591, DOI 10.1016/B978-0-444-59519-5.50118-0.

(51) Kalakul, S.; Cignitti, S.; Zhang, L.; Gani, R. VPPD-Lab: The Chemical Product Simulator. In Computer Aided Chemical Engineering; 2016, DOI 10.1016/B978-0-444-63683-6.00003-4.

(52) Jhamb, S.; Liang, X.; Dam-Johansen, K.; Kontogeorgis, G. M. A Model-Based Solvent Selection and Design Framework for Organic Coating Formulations. Prog. Org. Coatings 2020, 140, DOI 10.1016/j.porgcoat.2019.105471.

(53) Gani, R.; Nielsen, B.; Fredenslund, A. A Group Contribution Approach to Computer-Aided Molecular Design. AIChE J. 1991, 37 (9), 1318-1332, DOI 10.1002/aic.690370905.

(54) Gesthuizen, J. Formulators can move away from trial-and-error (accessed Oct 21, 2019). 
(55) Van Loon, S.; Fricker, B. Using HSP to Improve the Dispersibility of Pigments and Fillers TAGS: Dispersing Agents; 2018.

(56) Gani, R.; Hytoft, G.; Jaksland, C.; Jensen, A. K. An Integrated Computer Aided System for Integrated Design of Chemical Processes. Comput. Chem. Eng. 1997, 21 (10), 1135-1146, DOI 10.1016/S00981354(96)00324-9.

(57) Hansen, C. M. Hansen Solubility Parameters : A User's Handbook.; CRC Press, 2007.

(58) Abbott, S. Practical Formulation Science for Particle - Based Inks. Colloids and Interfaces 2019, 3 (23), 1-16.

(59) Scott, A. One Firm's Vision of the Future. C\&EN Glob. Enterp. 2019, 97 (28), 24-25, DOI 10.1021/cen-09728-feature3.

(60) Thiel, R. Digital assistant shines with paints and coatings expertise.

(61) Park, R. H.; Stearns, E. I. Spectrophotometric Formulation. J. Opt. Soc. Am. 1944, 34 (2), 112-113, DOI 10.1364/josa.34.000112.

(62) Rich, D. C. Computer-Aided Design and Manufacturing of the Color of Decorative and Protective Coatings. J. Coatings Technol. 1995, 67 (840), 53-60.

(63) Largo Innova AB. Products - Software - Largo (accessed Oct 21, 2019).

(64) Meyer, G.; Shimizu, C.; Eggly, A.; Fischer, D.; King, J.; Rodriguez, A. Computer Aided Design of Automotive Finishes. 10th Congr. Int. Colour Assoc. 2005, 685-688.

(65) Kim, D. B.; Lee, K. H. Computer-Aided Appearance Design Based on BRDF Measurements. CAD Comput. Aided Des. 2011, 43 (9), 1181-1193, DOI 10.1016/j.cad.2011.04.015.

(66) Carew, J. A. Modeling and Prediction of Service Life of Coating Systems for Industrial Environments. Jocca-Surface Coatings Int. 1994, 77 (12), 515.

(67) Busso, E. P.; Evans, H. E.; Wright, L.; McCartney, L. N.; Nunn, J.; Osgerby, S. A Software Tool for Lifetime Prediction of Thermal Barrier Coating Systems. Mater. Corros. 2008, 59 (7), 556-565, DOI 10.1002/maco.200804138.

(68) Chai, C.; De Brito, J.; Gaspar, P. L.; Silva, A. Statistical Modelling of the Service Life Prediction of Painted Surfaces. Int. J. Strateg. Prop. Manag. 2015, 19 (2), 173-185, DOI 10.3846/1648715X.2015.1031853.

(69) Dias, J. L.; Silva, A.; Chai, C.; Gaspar, P. L.; De Brito, J. Neural Networks Applied to Service Life Prediction of Exterior Painted Surfaces. Build. Res. Inf. 2014, 42 (3), 371-380, DOI 10.1080/09613218.2013.819551.

(70) Sakhnenko, N. D. Imitation Model for Predicting the Lifetime of Paint Coatings. Prot. Met. 1997, 33 (4), 393-397.

(71) Zhou, W.; Zhao, Y. G.; Li, W.; Qin, Q. D.; Hu, S. W.; Tian, B. Degradation Formula and Working Lifetime Prediction for High-Temperature Coating. Appl. Surf. Sci. 2006, 253 (5), 2565-2571, DOI 10.1016/j.apsusc.2006.05.027.

(72) Joly, A. M. Statistical Treatment of Data from the European Community Research on SelfStratification. Prog. Org. Coatings 1996, 28 (3 SPEC. ISS.), 209-222, DOI 10.1016/03009440(95)00598-6. 
(73) Beaugendre, A.; Degoutin, S.; Bellayer, S.; Pierlot, C.; Duquesne, S.; Casetta, M.; Jimenez, M. SelfStratifying Coatings: A Review. Prog. Org. Coatings 2017, 110, 210-241, DOI 10.1016/j.porgcoat.2017.03.011.

(74) Tusar, L., Tusar, M., Leskovsek, N. A Comparative Study of Polynomial and Neural-Network Modeling for the Optimization of Clear-Coat Formulations. Surf. Coatings Int. 1995, 78 (10), 427.

(75) Lin, L.; Guthrie, J. T.; He, W. D. Computer-Aided Modelling of Anti-Corrosion Coatings Formulations. J. Mater. Sci. 2003, 38 (5), 1097-1104, DOI 10.1023/A:1022366317952. 